\title{
Spatial Ability and Geometric Thinking of the Students of Teacher Training for Primary Education
}

\author{
Gabriela Pavlovičová ${ }^{1}$, Veronika Bočková ${ }^{2}$, Katarína Laššová ${ }^{3}$ \\ Department of mathematics, Constantine the Philosopher University in Nitra, Nitra, Slovakia
}

\begin{abstract}
In this article, we focus on geometric thinking and the solution of three spatial geometric tasks of future primary school teachers. The research sample consisted of 78 Bachelor's students at Constantine the Philosopher University in Nitra, Slovakia. The research findings show that future primary school teachers have a problem with geometrical thinking at higher levels and with solving spatial ability tasks, too. Using the statistical implicit analysis we revealed the connections between the students' solution of spatial ability tasks and the achieved level of geometric thinking according to van Hiele theory.
\end{abstract}

Keywords - geometric thinking, spatial ability, teacher training, implicative analysis.

\section{Introduction}

Spatial imagination and geometric thinking are some of the most essential human abilities useful for everyday life. Some professions require these special abilities. However, some current research shows that spatial ability and geometric thinking have a declining trend.

DOI: 10.18421/TEM111-49

https://doi.org/10.18421/TEM111-49

Corresponding author: Gabriela Pavlovičová, Constantine the Philosopher University in Nitra, Slovakia. Email: gpavlovicova@ukf.sk

Received: 25 October 2021.

Revised: 02 February 2022.

Accepted: 09 February 2022.

Published: 28 February 2022.

(c) BY-NC-ND (c) 2022 Gabriela Pavlovičová, Veronika Bočková \& Katarína Laššová; published by UIKTEN. This work is licensed under the Creative Commons AttributionNonCommercial-NoDerivs 4.0 License.

The article is published with Open Access at https://www.temjournal.com/
It can be caused by insufficient teacher readiness, who have to pass on knowledge to their learners. To effectively develop students' geometric thinking and spatial abilities, the teacher should have enough knowledge in this area and pedagogical skills to develop them. For these reasons, we decided to deal with the geometrical knowledge of future primary school teachers and special educators, students at the Constantine the Philosopher University in Nitra.

\section{Spatial Ability}

Spatial ability is a significant ability for everyday life. The term spatial ability can be understood very subjectively, and we can think it is the proper orientation in the forest, a new city, or reading maps. We know that spatial ability is vital for design, engineering, construction and architecture, interior modeling, and many others. However, it is crucial to define it clearly. Linn and Petersen [1] define spatial ability as a ,skill in representing, transforming, generating and recalling symbolic, non-linguistic information ". They also write that spatial ability is a mental process used to perceive, store, recall, create, edit, and communicate spatial images. Šedivý et al. [2] define spatial ability as imagining threedimensional geometric objects' properties, shape, position, size, and location in space.

Piaget and Inhelder [3] divide spatial ability into three phases. These phases depend on the pupil's development. At first, pupils work with 2D images, later they acquire skills with 3D objects, and finally, at the third phase, they learn the relationship between $2 \mathrm{D}$ and $3 \mathrm{D}$ objects.

Similar work has been conducted by Bruner [4]. Bruner [4] claims that shaping the mind is significant upon unlocking capacity by specialized cultural environment techniques.

Tomková et al. [5] divide spatial ability into three forms. General spatial imagination or intuitive spatial imagination is the lowest form of spatial ability. The higher form of spatial ability is geometric 
imagination. The highest form of spatial ability is spatial and geometrical thinking.

It is known that there are certain groups of people who think that spatial ability can only be innate. They claim that if the child is not born with spatial ability, it never gets it again. Of course, we cannot exclude this possibility. We are aware that even in early childhood, it is possible to form a spatial ability. The family has an impact on the formation of the child's spatial ability, too. Spatial ability and geometric knowledge can be made within the family by using new experiences. Reilly, Nauman and Andrews [6] claim that family members should lead children to use spatial language through various logical activities, didactic games, experiments, or competitions at home for the proper formation. Tomková et al. [5] write that this formation helps develop the spatial ability, mathematical and geometrical thinking, fantasy, and artistic inclinations.

During preschool and primary school education teacher plays an important role to develop pupils' spatial ability. Teachers should have sufficient knowledge of spatial imagination and they should be able to provide the necessary experience to their students. However, many types of research show that pre-primary, primary, and secondary school mathematics teachers often have low spatial ability. A similar result with the spatial ability of mathematics teachers achieved Hasan, Jakubowski, and Corey [7] by using the van Hiele model. For these reasons, activities for developing spatial ability must be included in students' teacher training.

Pupils and students learn about cube nets during the geometry lessons. A cube net is a twodimensional figure that can be folded into a threedimensional object. Šedivý et al. [2] wrote that six squares form cube nets in the plane and after their assembly, a cube is formed. The faces of the cube are joined on several sides. There are eleven different cube nets. Wardani and Toole [8] recommend that when pupils learn about cube nets, they are given one or two nets modeling that can be turned into a cube. The absence of this modeling may be the cause of students' misconceptions about cube nets.

\section{Geometrical Thinking}

Geometric thinking is the ability of pupils or students to use geometric concepts in maths lessons and various fields in real life. Geometric thinking is concerned with how people reason using the properties of geometric figures and spatial relationships. Various studies deal with students' geometric thinking. One of the most important and used studies of geometric thinking has been van Hiele's theory of geometric thinking since the 1950s. The theory forms the basis of the education content in various countries, and it is used in the curriculum in the United States, Russia, the Netherlands, Taiwan, and the Republic of South Africa.

Van Hiele's theory consists of five levels of geometric thinking. The theory supports learning geometry and helps to progress through the various levels of geometrical thinking. We, therefore, present the description of individual levels of geometric thinking. [9].

- Level 1 - Visualization: Students identify geometric shapes based on their complex visual perception or similarity to a known shape, the orientation of the shapes is dominant.

- Level 2 - Analysis: Students already know geometric shapes' properties and can create classes of geometric shapes based on their common properties. They define geometric shapes by listing all their properties, even those that are not necessary.

- Level 3 - Informal deduction: Students are aware of the relationships between the properties of individual geometric shapes. They also know that the properties of the shape are arranged and interconnected. They can formulate correct abstract definitions, which are characterized by their economy.

- Level 4 - Formal Deduction: Students understand the logical system of geometry and deduction; they know why the axioms, sentences, and definitions are essential. They can prove the claims at the secondary school level.

- Level 5 - Rigor: Students can compare different axiomatic systems and they understand nonEuclidean geometry. The students can use all types of proof.

From the basic ideas of van Hiele's theory of geometric thinking, it follows that the transition to a higher level is conditioned by mastering the lower level. The student's knowledge at one level is the subject of thinking at the next level. Each level of geometric thinking is characterized by specific terminology, expressions and relationships between knowledge. Pupils at different levels of geometric thinking cannot understand each other [9]. It is necessary to follow five phases of the teaching process (information, guided orientation, explication, free orientation, and integration) to progress to the next level of geometric thinking. The teacher's practical help can support not only the move to a higher level of geometric thinking but the better results in geometry, too [10]. 


\section{Empirical Researches Linking Spatial Ability and Geometric Thinking}

Pierre van Hiele and Dina van Hiele - Geldof determined the levels of the cognitive process in Euclidian geometry and created van Hiele's theory of geometric thinking in 1957. Many studies determined the level of geometrical thinking of different age categories: pre-schooler [11] first level primary school pupils [12] or second level of primary school pupils [13] or secondary school students [14]. Various studies show that the pupils' level of knowledge is influenced by the level of knowledge of their pre-service elementary mathematics teachers' [15], or mathematics teachers [16]. For this reason, many kinds of research also focus on determining the level of geometric thinking of mathematics teachers or future mathematics teachers. The level of geometric thinking of students of teacher training or in-service teachers for primary education was determined from Indonesia [17], Turkey [18], Ghana [19], Israel [20]. These researches confirm that students or teachers for primary education do not reach the required level of geometric thinking. The study by Eryurt and Güner [15] confirms that the level of geometric thinking has a positive correlation to constructivist-based teaching. Halat's research shows that female and male in-service elementary school teachers performed equally on the test. Based on Patkin's [20] study, there is a difference in geometric thinking levels of pre-service and inservice mathematics teachers at different points during their education in geometry.

Spatial ability is a critical cognitive ability. According to Mohler et al. [21], it is crucial for two primary reasons: "to teach the technical language" and "to develop the students' ability to visualize and solve problems in three dimensions". ReillyNeuman's research [22] shows that development, instruction, and practice of spatial ability can improve performance on spatial tasks. Some researchers have examined whether men and women differ in spatial ability, and this fact confirmed the study of Tsui et al. [23]. They researched students of the University of China and showed that men's score in The Mental Rotation Test is significantly higher than women's score.

Similar results of different spatial perceptions of women and men indicate Halpern and Collaer [24] and Kimura [25] in their books. It is generally known that pupils and students have problems with spatial ability. Noviana and Hadi's [26] research shows that the problems with learning geometry are caused by the learners' lack of ability to express their ideas and have trouble concentrating. Residential environments and formal education may also cause it. Researchers and teachers think that technological conveniences can be a suitable tool for developing spatial imagination. However, Noviniana and Hadi [26] compared mathematical spatial ability treated with the Model Van Hiele Based Geogebra and the conventional models. It turned out that students' mathematical spatial ability was in both groups the same. On the other hand, teachers' low spatial ability can affect the pupils' spatial ability. Many mathematics teachers and pre-primary and primary school teachers have lower levels of spatial skills than would be necessary. According to Marchis [27], these teachers must develop their spatial abilities. The research results [28] show that Van Hiele learning model could positively impact students' spatial ability.

Van Hiele's theory has been applied to the understanding three - dimensional geometry by Gutierrez et al. [29]. The results of Saads and Davis's [30] research confirm the relationship between spatial ability and van Hiele's levels of geometric thinking. Much actual research deals with spatial ability development using programs based on van Hiele's theory. July [31], in his dissertation thesis, demonstrates that interactive computer program Geometer's Sketchpad, which is based on the van Hiele theory, helps students improve their spatial skills and progress through the level of geometric thinking. Meng and Idris [32] achieved similar results. In their study, they confirm that achievement in solid geometry could be enhanced through phasebased instruction using manipulatives and The Geometer's Sketchpad, too. The Armahs' research [33] with pre-service teachers confirms that low geometry learning experiences also lead to inadequate spatial ability experience. Similarly, Trimurtini et al. [34] state that geometry learning that pays attention to geometric thinking is expected to provide a meaningful learning experience to achieve spatial ability. Based on the mentioned research, it is important to develop geometric thinking to develop spatial ability.

\section{Research Design}

The research consists of two parts: identifying the level of geometric thinking of the pedagogy students and determining their achievement in solving spatial ability tasks.

\section{Research Goals}

The following research goals have been stated:

- To determine the level of geometric thinking of future primary school teachers.

- To design spatial ability tasks and quantitatively evaluate the solution of these tasks. 
- To reveal the connections between the solution of three spatial ability tasks with the attained level of geometric thinking according to Van Hiele's theory.

\section{Research Sample}

The research was realized in September 2021. The research sample consisted of 78 Bachelor's students at Constantine the Philosopher University in Nitra, students of Teacher training for preschool and primary education. The research was carried out within the subject of mathematics, intended for the first year of the university studies. The students finished their secondary school studies at various types of secondary schools. There were $32 \%$ of students who studied in grammar schools, $24 \%$ graduated in vocational schools and $44 \%$ finished pedagogic high school.

\section{Research Tools}

\section{Van Hiele geometry test}

The students' geometric thinking levels were determined using the van Hiele geometric test, which professor Zelman Usiskin created in 1980. The test was applied with the consent of the professor and we listed on each copy of the test: "Copyright (C) 1980 by the University of Chicago". The test contains twentyfive multiple-choice items - five items for each of the five levels of geometric thinking. The group of items at individual levels corresponded to students' knowledge according to the van Hiele model. Student passes a level if he or she gets three or four out of five questions correct. In our research, we use the criterion of three correct questions and a modified way of assessing. It means that the level of geometric thinking is assigned to each student.

\section{Spatial Ability Tasks}

All three tasks were related to the cubes and cube nets. The first task was focused on the rotation of the dice according to the fields of the plan. In the second part of the first task, students had to complete the numbers on the cube nets created from the dice in the task assignment. The second task was oriented to adding the dots in the dice nets. The third task deals with folding the nets into a cube.

The following tasks were solved by the students:

\section{Task 1}

To the individual fields of the plan, write the number of dots on the face when you rotate dice $90^{\circ}$ in the direction of the plan. a.

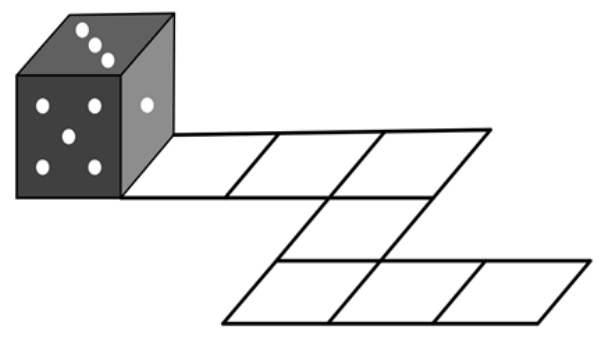

Insert the suitable number of dots on the dice's individual faces in the picture. b.

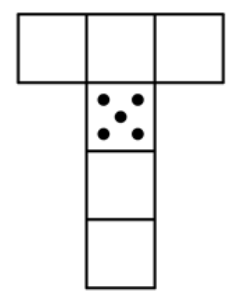

c.

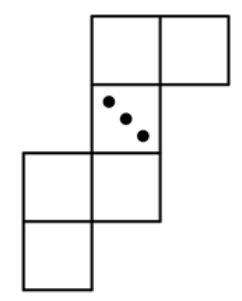

Task 2

Which of the figures below can be folded into a cube? Cross out the wrong cube net. Insert suitable numbers in each square of the cube net. a.
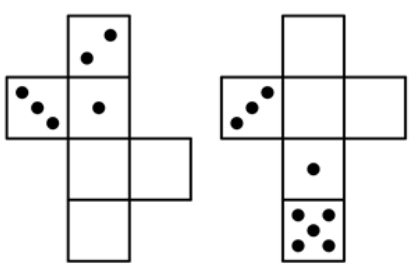

d.

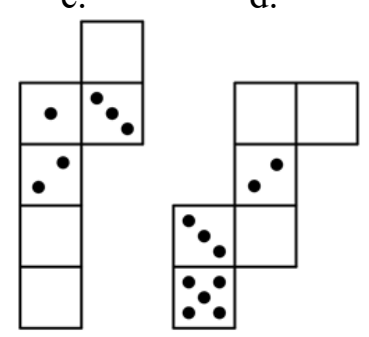

Task 3

Write which shapes will be joined (merged) after assembling the cube.

a. Cube net A

Point $\mathrm{F}$ is joined to points.

Point $\mathrm{G}$ is joined to points

Line $\mathrm{FG}$ is joined to line.

b. Cube net $B$

Point $\mathrm{F}$ is joined to points.

Point $\mathrm{G}$ is joined to points

Line $\mathrm{FG}$ is joined to line
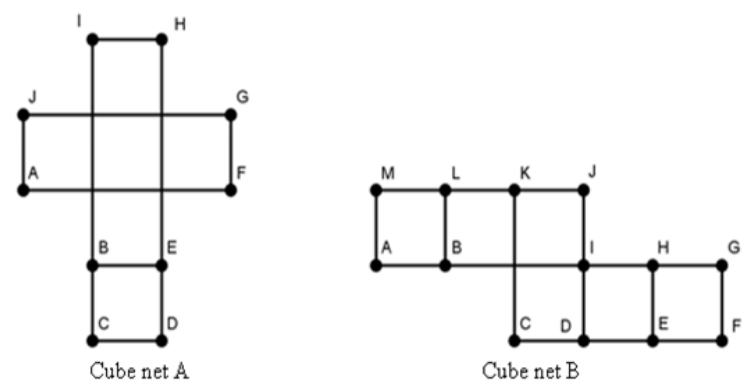


\section{Statistical Implicative Analysis Methods}

In addition to the standard quantitative evaluation, statistical implicative analysis methods were used in the evaluation. These methods offer an original statistical approach based on Implication Intensity measure, dedicated to rule extraction and analysis [35]. For deeper analysis of relationships between stated didactical variables we used C.H.I.C. statistical software (Classification Hiérarchique Implicative et Cohésitive).

The following didactic variables were stated in the a priori analysis:

Type L - level of geometrical thinking of the students

- L1 - student reaches visualization level

- L2 - student reaches analysis level

- L3 - student reaches the informal deductive level

- L4 - student reaches the formal deductive level

Type 1 - students' solution of Task 1

- 1_a_CS - student correctly solves the subtask a

- 1_b_CS - student correctly solves the subtask b

- 1_c_CS - student correctly solves the subtask c

- 1_CS - student correctly solves Task 1

Type 2 - students' solution of Task 2

- 2_a_CS - student correctly solves the subtask a

- 2_b_CS - student correctly solves the subtask b

- 2_c_CS - student correctly solves the subtask c

- 2_d_CS- student correctly solves the subtask d

- 2 - CS - student correctly solves the Task 2

Type 3 - students' solution of Task 3

- 3_a_CS - student correctly solves the subtask a

- 3_b_CS - student correctly solves the subtask b

- 3_CS - student correctly solves the Task 3

\section{Data Analysis and Interpretation of Results}

Every teacher should achieve a higher level of geometric thinking than their potential pupils, and they should provide assistance in learning geometry and developing their geometric thinking. Pupils in the first stage of primary school can achieve visualization or analysis level. Therefore, it would be appropriate for primary school teachers to reach at least the level of informal deduction. For example, Knight [36] assumed the same level of geometric thinking for these teachers.

Figure 1. shows the percentage representation of students at each level of geometric thinking. As we can see, most students $(37.2 \%)$ are at visualization level and $2.6 \%$ of pupils did not reach this level. The level of analysis was achieved by $25.6 \%$ of students, and it means that only $34.7 \%$ of students achieved the required level of geometric thinking.

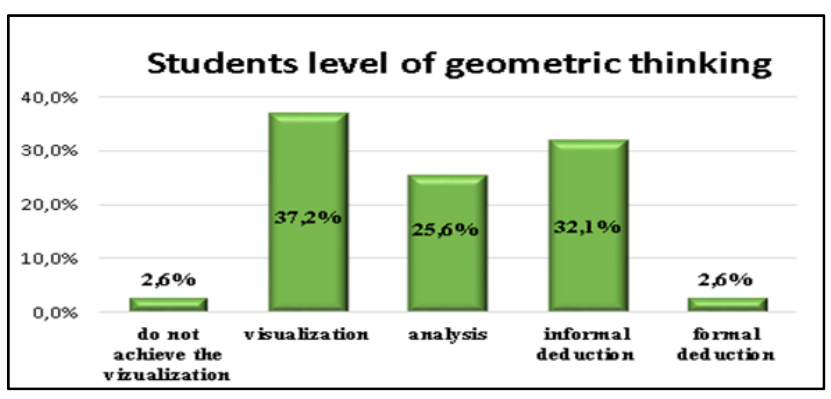

Figure 1. Students' level of geometric thinking according to van Hiele's theory.

Figure 2. presents the achievement of students in solving three spatial ability tasks. As we can see, the students had problems with solving the first and the third task, which correctly solved only $15.4 \%$ of them.

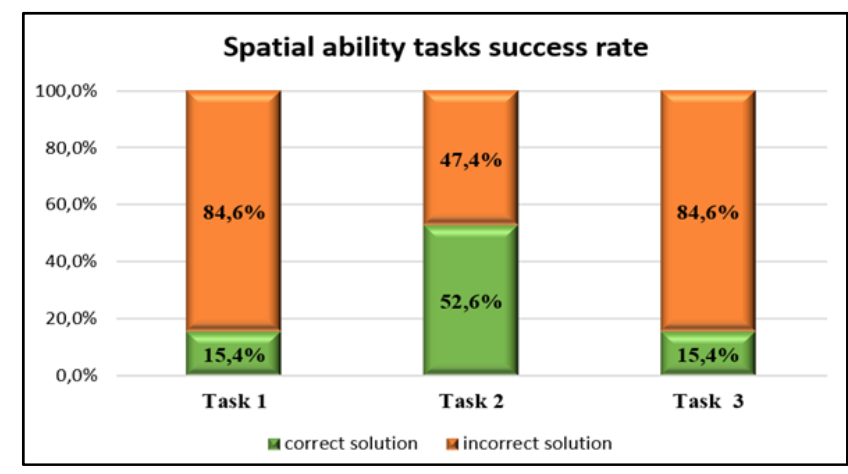

Figure 2. Spatial ability tasks success rate

Figure 3. presents the achievement of students in solving individual subtasks of each task. The most demanding task for the students was to write the number of dots to the plan. They also had the problem of writing which points and lines would be joined after assembling the cube in non-standard cube nets (subtasks $3 a$ and $3 b$ ).

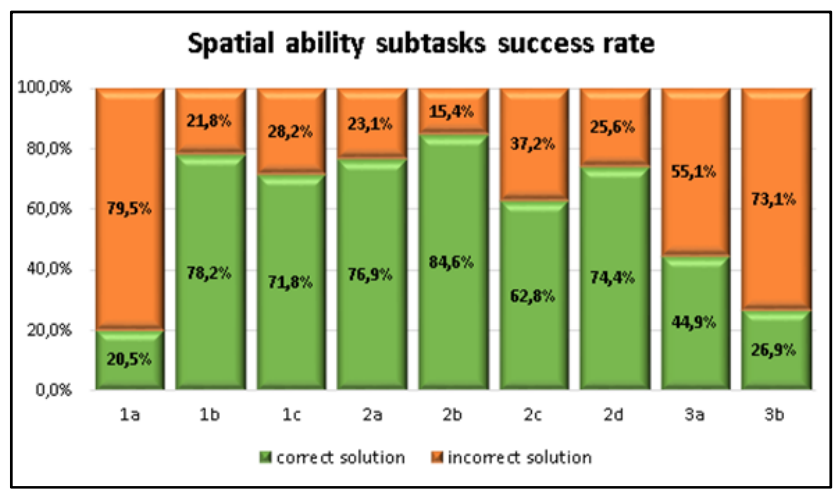

Figure 3. Spatial ability subtasks success rate

The statistical program C.H.I.C was used to visualize connections between the solution of spatial ability tasks and the achieved level of geometric thinking. Implicative trees were produced based on the mentioned didactic variables.

There is the implicative tree for levels of geometric thinking and complete right solutions of three spatial 
ability tasks in Figure 4. The graph confirms the significant statistical implications between the analysis level and correct solutions of the tasks. The strongest hierarchy is between the variables L2 and 1_CS $($ cohesion $=0.77)$. It means that a student who achieved the analysis level can correctly solve Task 1. Then the sequence of implications $\left(\left(\mathrm{L} 2 \rightarrow 1 \_\mathrm{CS}\right) \rightarrow 2 \_\mathrm{CS}\right) \rightarrow 3$ CS is lower but still significant. It confirms that if the student achieved the analysis level and correctly solved Task 1, then he/she correctly solved Task 2 and Task 3 .

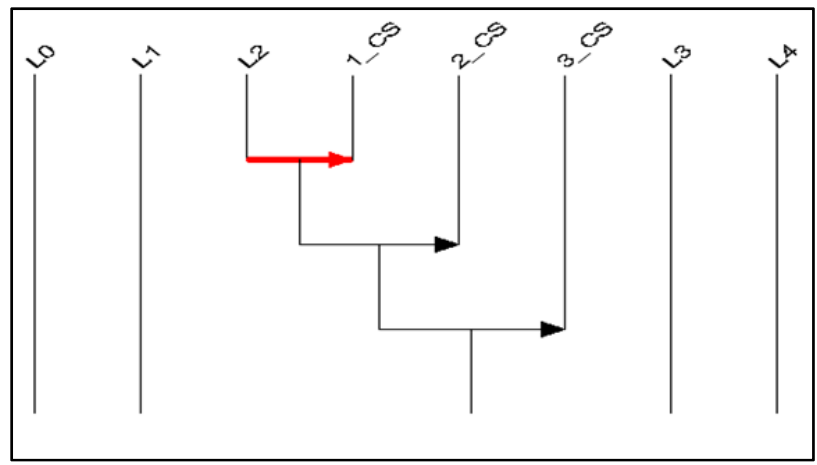

Figure 4. Implicative tree for the level of geometric thinking and complete, correct solutions of spatial ability tasks

The implication trees of subtasks for each spatial ability task shows significant knots at the analysis level of geometric thinking. Figure 5. gives the implication tree for Task 1. The graph shows that subtask $1 \mathrm{~b}$ implies subtask $1 \mathrm{a}($ cohesion $=0.99)$. The correct solution of both tasks is implied by subtask 1c. The sequence of implications L $2 \rightarrow\left(1 \_c\right.$ CS $\rightarrow\left(1 \_b \_C S \rightarrow 1 \_\right.$a $\left.\left.C S\right)\right)$ confirms that if students achieve the level of analysis, they correctly solve all subtasks of the Task 1. From the analysis of stated variables type $L$ and type 1 we can see, that if students insert the suitable number of dots on the cube net $\mathrm{C}$ (subtask 1C) which is for students nonstandard cube net, than students correctly insert suitable numbers of dots on the standard cube net $B$ (subtask 1B) and they write the correct number of dots on the plan, too.

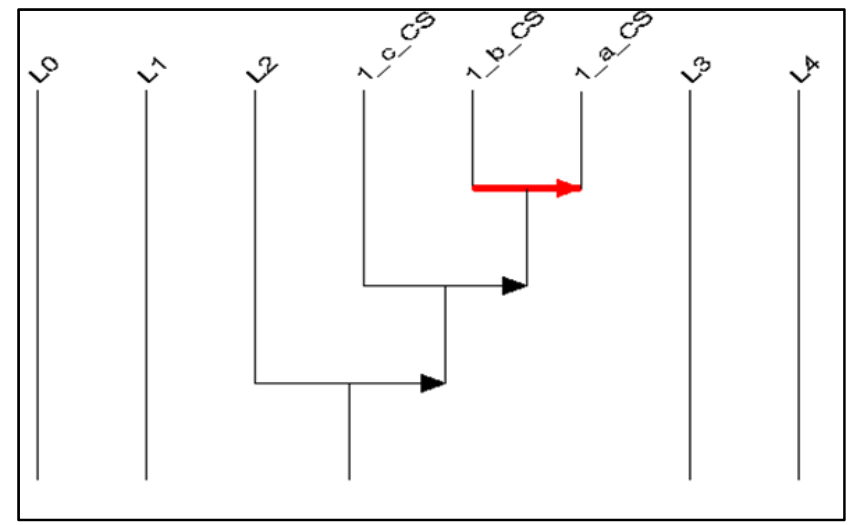

Figure 5. Implicative tree for the level of geometric thinking and correct solutions subtasks of Task 1
Interesting results are shown in Figure 6. for Task 2. As can be seen from the graph, there is a significant statistical implication between the insertion of suitable numbers of the cube net $d$ and insertion of suitable numbers of the cube net $b$ (implication 2_d_CS and 2_b_CS). This implication confirms that if students correctly insert numbers in each square of the non standard cube net (subtask 2D), then they correctly insert numbers in each square of the standard cube net (subtask 2B). This implication is caused by the fact that students operate by the type of net cube B more than with type of cube net $\mathrm{D}$. The group of implications (cohesion = 0.94) L2, 2_d, 2_b, 2_c, 2_a also confirm that the students at the level of analysis can correctly solve the subtasks of Task 2.

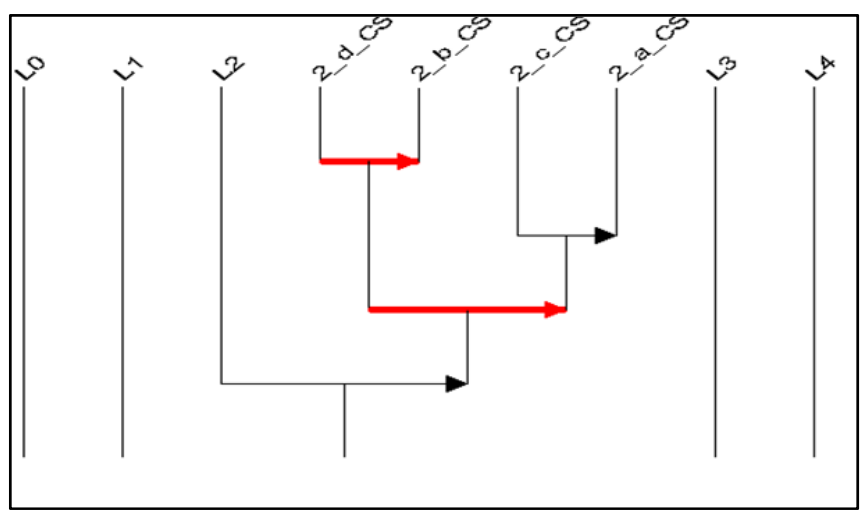

Figure 6. Implicative tree for the level of geometric thinking and correct solutions subtasks of Task 2

There are connections between the level of geometric thinking and subtask Task 3 in Figure 7. There is significant connection between variables 3_b_CS and 3_a_CS $($ cohesion $=1)$. It means that if students correctly joined the points and lines of non standard net cube B, they correctly joined the points and lines of standard net cube A. The second strongest rule $\left(3\right.$ b_CS $\rightarrow 3$ a $\_$CS $) \rightarrow$ L2 $($ cohesion $=$ 0.89 ) has the following meaning: if students can solve subtask $3 \mathrm{~b}$ and $3 \mathrm{a}$, they are at the level of analysis.

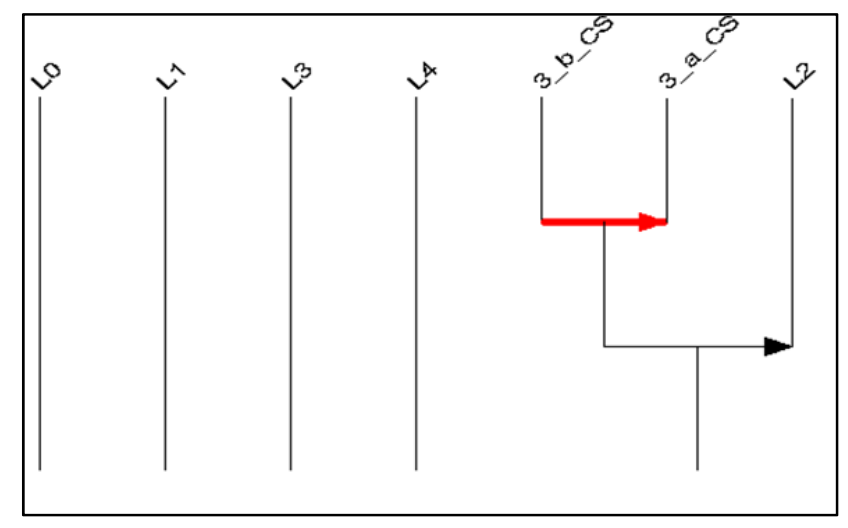

Figure 7. Implicative tree for the level of geometric thinking and correct solutions subtasks of Task 3 


\section{Conclusions}

The research was focused on determining the level of geometric thinking of future primary school teachers and their solutions of three spatial ability tasks. The connections between the spatial ability tasks solutions with the attained level of geometric thinking according to Van Hiele's theory were investigated, too. As was mentionded above, many researchers [17], [18] confirm that these students have thinking difficulties at higher levels of geometric thinking. A lot of students have a problem with spatial ability, too. Armahs [33] declare that low geometry learning experiences cause low spatial ability.

Our research findings show that future primary school teachers have a problem with geometrical thinking at higher levels. Only $34.7 \%$ of students in our research sample achieved the informal deduction level. These students have a problem with the logical system of geometry and the proofs in it. Similar results were obtained in the academic year 2019/2020 at the Constantine the Philosopher University in Nitra in Slovakia and in other countries, too [22], [36].

Students in our research also had problems with solving spatial ability tasks focused on working with cubes and cube nets. Students have been shown to be better able to cope with the cube nets found in mathematics textbooks at primary and secondary schools. On the one hand, it is natural, but on the other hand it points to the fact that in school education we tend to work only in a standard educational environment, which insufficiently helps to develop the spatial imagination of students. We can even slow down its natural development in this way. For the mentioned reasons, it is necessary to include the subject within the framework of spatial ability development in the further study in teacher training study programs. It is also verified by Marchis [27], which claims that developing spatial ability is necessary for these students.

The connections between the solution of spatial ability tasks and the achieved level of geometric thinking according to van Hiele's theory were also revealed. From the implicative tree, it can be concluded that geometric thinking affects the solution of spatial ability tasks. The implication analysis shows that if students achieved the analysis level, they correctly solved the spatial ability tasks. It can be said that our spatial ability tasks are on the analysis level according to van Hiele theory of geometric thinking.
Our findings are in line with the results of other foreign researchers [30,31,32]. These results have shown a significant increase in the attention in the preparation of future primary school teachers.

We consider it very important to create for students a creative and varied learning environment using non-standard tasks in order to develop the spatial imagination and geometric thinking of students at all levels of education.

\section{Acknowledgements}

This paper was created with support of projects UGA: VII/3/2021; UGA: VII/9/2021 and KEGA: O19UKF$4 / 2020$.

\section{References}

[1]. Linn, M. C., \& Petersen, A. C. (1985). Emergence and characterization of sex differences in spatial ability: A meta-analysis. Child development, 14791498.

[2]. Šedivý, O., Pavlovičová, G., Rumanová, L., \& Vallo, D. (2007). Stereometria: umenie vidiet' a predstavovat' si priestor. Nitra: UKF v Nitre.

[3]. Piaget, J. (2013). Mental Imaginery in the Child: Selected Works vol 6. Routledge.

[4]. Bruner, J. S. (1964). The course of cognitive growth. American psychologist, 19(1), 1.

[5]. Tomková, V. et al. (2014) Priestorová predstavivost' v školskej praxis. Edukacja-Technika-Informatyka, 5(1), 8-40.

[6]. Reilly, D., Neumann, D. L., \& Andrews, G. (2017). Gender differences in spatial ability: Implications for STEM education and approaches to reducing the gender gap for parents and educators. In Visualspatial ability in STEM education (pp. 195-224). Springer, Cham.

[7]. Unal, H., Jakubowski, E., \& Corey, D. (2009). Differences in learning geometry among high and low spatial ability pre-service mathematics teachers. International Journal of Mathematical Education in Science and Technology, 40(8), 9971012.

[8]. Wardani, I., Tolle, H., \& Aknuranda, I. (2019). Evaluation of an Educational Media on Cube Nets Based on Learning Effectiveness and Gamification Parameters. International Journal of Emerging Technologies in Learning (iJET), 14(14), 4-18.

[9]. Usiskin, Z. (1982). Van Hiele levels and achievement in secondary school geometry. University of Chicago, Chicago, Il.

[10]. Van Hiele, P. M. (1999). Developing geometric thinking through activities that begin with play. Teaching children mathematics, 5(6), 310-316.

[11]. Clements, D. H., \& Sarama, S. (2007). Early childhood mathematics learning. Second handbook of research on mathematics teaching and learning. US: Information Age Publishing. 
[12]. Andini, S., \& Fitriana, L. (2018, March). Elementary school students visual spatial comprehension based on van Hiele Theory: the case in Madiun, East Java, Indonesia. In Journal of Physics: Conference Series (Vol. 983, No. 1, p. 012097). IOP Publishing.

[13]. Hardianti, D., Priatna, N., \& Priatna, B. A. (2017, September). Analysis of Geometric Thinking Students' and Process-Guided Inquiry Learning Model. In Journal of Physics: Conference Series (Vol. 895, No. 1, p. 012088). IOP Publishing.

[14]. Haviger, J., \& Vojkůvková, I. (2014). The van Hiele geometry thinking levels: gender and school type differences. Procedia-Social and Behavioral Sciences, 112, 977-981.

[15]. UYGUN, T., \& GÜNER, P. (2021). Van Hiele Levels of Geometric Thinking and ConstructivistBased Teaching Practices. Mersin Üniversitesi Eğitim Fakültesi Dergisi, 17(1), 22-40.

[16]. Clements, D. H. (2003). Teaching and learning geometry. In J. Kilpatrick, W. G. Martin, \& D. Schifter (Eds.), A research companion to principles and standards for school mathematics (pp. 151-178). Reston, VA: National Council of Teachers of Mathematics.

[17]. Jupri, A. (2018, May). Using the Van Hiele theory to analyze primary school teachers' written work on geometrical proof problems. In Journal of Physics: Conference Series (Vol. 1013, No. 1, p. 012117). IOP Publishing.

[18]. Yilmaz, G. K., \& Koparan, T. (2016). The Effect of Designed Geometry Teaching Lesson to the Candidate Teachers' Van Hiele Geometric Thinking Level. Journal of Education and Training Studies, 4(1), 129-141.

[19]. Armah, R. B., Cofie, P. O., \& Okpoti, C. A. (2017). The geometric thinking levels of pre-service teachers in Ghana. Higher Education Research, 2(3), 98-106.

[20]. Patkin, D., \& Barkai, R. (2014). Geometric thinking levels of pre-and in-service mathematics teachers at various stages of their education. Educational Research Journal, 29(1/2), 1-26.

[21]. Mohler, J. L., \& Miller, C. L. (2008). Improving Spatial Ability with Mentored Sketching. Engineering Design Graphics Journal, 72(1), 19-27.

[22]. Reilly, D., Neumann, D. L., \& Andrews, G. (2017). Gender differences in spatial ability: Implications for STEM education and approaches to reducing the gender gap for parents and educators. In Visualspatial ability in STEM education (pp. 195-224). Springer, Cham.

[23]. Ming, T., Venator, E., \& Xu, X. Y. (2014). Mental Rotation Test Performance of Chinese Male and Female University Students. Chinese Studies, 3(2), 41-46.
[24]. Halpern, D. F. (2000). Sex differences in cognitive abilities. Psychology press.

[25]. Kimura, D. (2000). Sex and cognition. MIT press.

[26]. Noviana, W., \& Hadi, W. (2021, May). The Effect of Van Hiele Learning Model Based Geogebra on Students' Spatial Ability. In 1st Annual International Conference on Natural and Social Science Education (ICNSSE 2020) (pp. 14-19). Atlantis Press.

[27]. Marchis, I. (2017). Pre-Service Primary School Teachers' Spatial Abilities. Acta Didactica Napocensia, 10(2), 123-130.

[28]. Pujawan, I., Suryawan, I., \& Prabawati, D. A. A. (2020). The Effect of Van Hiele Learning Model on Students' Spatial Abilities. International Journal of Instruction, 13(3), 461-474.

[29]. Gutiérrez, A., Jaime, A., \& Fortuny, J. M. (1991). An alternative paradigm to evaluate the acquisition of the van Hiele levels. Journal for Research in Mathematics education, 22(3), 237-251.

[30]. Saads, S., \& Davis, G. (1997). Spatial abilities, van Hiele levels \& language use in three dimensional geometry. In Proceedings of the 21st Conference of the International Group for the Psychology of Mathematics Education; Helsinki, Finland, $14^{\text {th }}-19^{\text {th }}$ of July (pp. 104 - 111). Finland: University of Helsinki.

[31]. July, R. A. (2001). Thinking in three dimensions: Exploring students' geometric thinking and spatial ability with the Geometer's Sketchpad. Florida International University.

[32]. Meng, C. C., \& Idris, N. (2012). Enhancing students' geometric thinking and achievement in solid geometry. Journal of Mathematics Education, 5(1), 15-33.

[33]. Armah, R. B., Cofie, P. O., \& Okpoti, C. A. (2018). Investigating the Effect of van Hiele Phase-Based Instruction on Pre-Service Teachers' Geometric Thinking. International journal of Research in Education and Science, 4(1), 314-330.

[34]. Trimurtini, T., Waluya, S. B., Walid, W., Dwidayati, N. K., \& Kharisudin, I. (2021). Measuring Spatial Ability and Geometric Thinking Level of Prospective Elementary School Teachers Using the Rasch Model. Ilkogretim Online, 20(1), 948-957.

[35]. Gras, R. et al. (2008). Statistical Implicativa Analysis. Theory and Applications. Germany: Springer.

[36]. Knight, K.C. (2006). An investigation into the change in the van Hiele levels of understanding geometry of pre-service elementary and secondary mathematics teachers. Unpublished Master Thesis. The University of Maine. 